\title{
Arterial lactate levels and their prognostic value in patients undergoing pulmonary thromboendarterectomy
}

\author{
Cristhian Felipe Ramírez-Ramos (101,a, , Clara Inés Saldarriaga-Giraldo (iD2,b , Manuela Yepes-Calderón ${ }^{3, c}$,

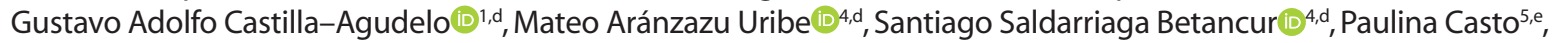

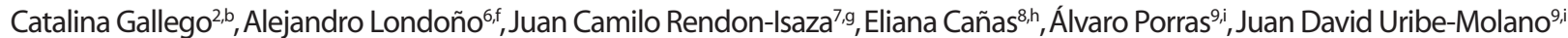

Received: April 3, 2021

Acepted: May 24, 2021

Author affiliations

Department of Cardiology, Universidad Pontificia Bolivariana, Clínica CardioVID. Medellin, Colombia. Department of Cardiology and Heart Failure, Universidad Pontificia Bolivariana, Clínica CardioVID. Universidad de Antioquia. MedeUlin, Colombia.

Universidad de Antioquia. Medellin, Colombia.

Department of Internal Medicine, Universidad Pontificia Bolivariana, Clínica CardioVID. Medellin, Colom bia.

Department of Anesthesiology Universidad Pontificia Bolivariana, Clínica CardioVID. Medellin, Colom-

Department of Pulmonology and Pulmonary Hypertension Clinic, $\mathrm{Cl}$ nica CardioVID. Medellin, Colombia Cardiovascular Surgery Department, Universidad Pontificia Bolivariana Clínica CardioVID. Medellin Colombia.

Department of Epidemiology, Universidad Pontificia Bolivariana, Clínica CardioVID. Medellin, Colom-

bia. dicine and Cardiovascular Intensive Care, Clínica CardioVID. Medellin, Colombia.

Internist, Cardiology Fellow.

Internist and Cardiologist.

General Physician.

Internal Medicine Resident Physician.

Resident Physician.

Internist and Pneumologist.

Cardiovascular Surgeon.

Nurse, Epidemiologist.

Nurse, Epidemiologist.
Internist, Specialist in Critical

Internist, Spec

Corresponding author

Department of Cardiology,

Universidad Pontificia Bolivariana,

Clínica CardioVID.

Circular 72 \#38-40 Medellín

Colombia.

310-202-2516

Email

cristhianramos1989@hotmail.com cfrr89@gmail.com

Conflicts of interest

The authors declare that they have no competing interests

\section{Financing}

This research did not receive any specific grant from funding agencies in the public, commercial, or not-forprofit sectors.

Citar como:

Ramirez Ramos CF, Saldarriaga-Giraldo $\mathrm{Cl}$, Yepes-Calderón M, Castilla-Agudelo GA, Aránzazu Uribe M, Saldarriaga Betancur S, etal Arteriallactate evels and their prognostic value Bevels and their prognostic value in patients undergoing pulmonary thromboendarterectomy. Arch Per Cardiol Cir Cardiovasc. 2021;2(2):96102. doi: 10.47487/apсyccv.v2i2.131

\section{ABSTRACT}

Objective. Evaluate the change of lactate levels and its prognostic role in the postoperative period of patients undergoing pulmonary thromboendarterectomy. Methods. Retrospective study between 2001 and 2019. Patients older than 18 years and who underwent pulmonary thromboendarterectomy were included. The $U$ Mann Whitney test was performed to evaluate the change between lactate levels, and Cox regression analysis to evaluate the relationship with mortality. Areas under the curve were constructed for lactate levels. Results. Seventy-three patients were operated on during the study period. Median age was 51 years, 55\% female. The median lactate on days 1 was $4.65 \mathrm{mml} / \mathrm{L}$ and on day 2 it was $1.62 \mathrm{mml} / \mathrm{L}$ with a change of $2.87 \mathrm{mml} / \mathrm{L}$. No differences were found between the levels measured on day 1 and 2 between the people who died and those who did not on day 30 . In the multivariate regression of COX, no relationship with mortality was found. The area under the curve shows regular performance on both day 1 and day 2 in predicting mortality outcomes. Conclusions. The behavior of the lactate in patients undergoing pulmonary thromboendarterectomy shows a rapid change during the first hours after the procedure. No role was found as a predictor of mortality neither in-hospital nor in follow-up.

Keywords. Pulmonary Hypertension; Pulmonary Embolism; Endarterectomy; Lactic Acid (source: MeSH NLM).

RESUMEN

\section{Niveles de lactato arterial y su valor pronóstico en pacientes sometidos a tromboendarterectomía pulmonar}

Objetivo. Evaluar el cambio de los niveles de lactato y su rol pronóstico en el posoperatorio de pacientes sometidos a tromboendarterectomía pulmonar. Métodos. Estudio retrospectivo entre 2001 y 2019. Se incluyeron pacientes mayores de 18 años que fueron sometidos a tromboendarterectomía pulmonar. Para evaluar el cambio entre los niveles de lactato se realizó la prueba de U Mann Whitney. Para evaluar la relación con la mortalidad se realizó un análisis multivariado de Cox. Se construyeron áreas bajo la curva para los niveles de lactato. Resultados. Setenta y tres pacientes fueron operados durante el período de estudio. La mediana de edad fue de 51 años, $55 \%$ mujeres. La mediana de lactato en el día 1 fue de 4,65 mmL/L y en el día 2 fue de $1,62 \mathrm{mmL} / \mathrm{L}$ con un cambio de $2,87 \mathrm{mmL} / \mathrm{L}$. No se encontraron diferencias entre los niveles medidos el día 1 y 2 entre las personas que murieron y las que no al día 30 hospitalario. En la regresión multivariada de COX no se encontró relación con la mortalidad. El área bajo la curva muestra un desempeño regular tanto en el día 1 como en el día 2 para predecir el resultado de la mortalidad en especial intrahospitalaria. Conclusiones. El comportamiento del lactato en pacientes sometidos a tromboendarterectomía pulmonar muestra un cambio rápido durante las primeras horas posteriores al procedimiento. No se encontró que sea un predictor de mortalidad ni hospitalaria ni durante el seguimiento.

Palabras clave. Hipertensión Pulmonar; Embolia Pulmonar; Endarterectomía; Ácido Láctico (fuente: DeCS BIREME). 
A Ithough the exact incidence and prevalence is unknown, it is estimated that around $4-5 \%$ of patients who suffer an acute pulmonary embolism develop chronic thromboembolic pulmonary hypertension (CTPH). This disease is characterized by intraluminal organization of the thrombus, fibrotic scar-like stenosis, and vascular remodeling (1). This disease is associated with a poor prognosis and when the mean pulmonary pressure reaches $50 \mathrm{mmHg}$ or more, 3-year mortality is $90 \%{ }^{(2)}$.

Pulmonary thromboendarterectomy remains the preferred treatment and is a potentially curative option for patients with chronic thromboembolic pulmonary hypertension. Despite this, only 0.9 to 1 procedure are performed per million inhabitants in the United States and 1.7 per million in European countries ${ }^{(3)}$. The benefit of the procedure has been established in multiple series, achieving improvement in functional status, exercise capacity, and hemodynamic variables with mortality rates of the procedure in high-experience centers of $2.2 \%{ }^{(4)}$.

Cardiopulmonary bypass (CPB) using a heart-lung machine (HLM) represents a standard technique in modern cardiac surgery. CPB provides adequate systemic oxygenation and perfusion during cardiac operation through the adjustment of flow rate, temperature, oxygen concentration, and hemoglobin level ${ }^{(5)}$. Intraoperative events, including surgical techniques, methods used in myocardial protection, and CPB, can affect surgical outcomes. Altered mental status and decreased urine output are signs of tissue hypoperfusion; however, an adequate and timely assessment of such signs cannot be carried out during cardiac operation. Lactate is an end product of anaerobic glycolysis from oxygen deficit and tissue hypoperfusion. It is an obtainable surrogate marker of tissue hypoxia and disease severity and is considered an index marker of circulatory shock ${ }^{(6)}$.

Since the early studies by Weil (7) and other authors ${ }^{(8)}$, lactate concentrations have been used extensively as a marker in critically ill patients ${ }^{(9)}$. Even elevations of $>1.5 \mathrm{mmol} / \mathrm{L}$ have been associated with higher mortality rates ${ }^{(10)}$. In the particular shock scenario, regardless of its mechanism, this molecule is a marker of the hypoperfusion state and the degree of increase is directly related to the severity and higher mortality rates ${ }^{(11)}$.

Moreover, an elevated lactate level is observed during cardiac operation with CPB in a bimodal distribution. Type $A$ hyperlactatemia can occur during or soon after the initiation of CPB tissue due to hypoperfusion. Meanwhile, type B hyperlactatemia can be observed 4-14 $\mathrm{h}$ after surgery when a patient is admitted to an intensive care unit (ICU) under adequate oxygen delivery owing to increased substrate utilization ${ }^{(12)}$. A higher lactate level during CPB reflects inadequate tissue perfusion, which may be associated with poor surgical outcomes
Increased lactate concentrations are also associated with an increased risk of morbidity and death in pediatric patients undergoing cardiac surgery ${ }^{(13)}$ as well as in patients undergoing coronary bypass procedures (CABG) ${ }^{(14)}$. Hyperlactatemia (defined as levels $>2 \mathrm{mmol} / \mathrm{L}$ ) has been reported in $36 \%$ of cardiac surgery patients and is a predictor of death ${ }^{(15)}$.

Data on the kinetics of this molecule and its prognostic significance are unknown in patients undergoing pulmonary thromboendarterectomy. The objective of the present study was to evaluate the change of lactate and establish its prognostic role as a predictor of global and in-hospital death in patients undergoing pulmonary thromboendarterectomy in a cardiovascular referral center.

\section{Materials and methods}

Retrospective cohort study between January 2001 and November 2019 of patients > 18 years of age undergoing pulmonary thromboendarterectomy in a referral center for cardiovascular care. The patients were chosen for the procedure according to a multidisciplinary evaluation with the intervention of cardiovascular surgeons, cardiologists, specialists in heart failure and pulmonologists from the pulmonary hypertension clinic, considering functional class, accessibility of thrombotic lesions, hemodynamic status and comorbidities. Data were collected from the index hospitalization, related to the surgical procedure and its complications, including mortality. Lactate levels were recorded immediately after the surgical procedure and 24 hours later. The data included in the analysis were demographic and clinical variables, as well as characteristics related to the procedure and change in lactate levels. Continuous variables are presented as mean with standard deviation (SD) or as median and interquartile range [IQR] according to their distribution.

To evaluate the change (delta) between lactate levels on day 1 and day 2, the U Mann Whitney test was performed. To evaluate whether the change between day 1 and day 2 in lactate levels was associated with global mortality as in-hospital (first 30 days), a Cox regression analysis was performed. The model included age, sex, functional class, hemodynamic data such as pre and postsurgical mean pulmonary arterial pressure, preand postsurgical pulmonary and systemic vascular resistances, surgical times, mechanical ventilation time, the presence of edema of reperfusion and length of stay in intensive care unit. The Hazard Ratio (HR) calculated for lactate levels were adjusted for the variables included in the model. Areas under the curve (AUC) were constructed to assess lactate performance as a predictor of mortality. In addition, a linear regression was performed to establish whether lactate levels were related to days of 
mechanical ventilation. All analyzes were carried out using the SPSS version 22.0 statistical program.

The present study was approved by the institutional ethics committee and the Universidad Pontificia Bolivariana (minute 16 2020) and Clínica CardioVID, according to the research operative manual and resolution 8430/1993.

\section{Results (Central figure)}

Over a period of 18 years, 73 patients underwent pulmonary thromboendarterectomy. The median age was 51 years, $55 \%$ of the patients were women; $93 \%$ of the population had a history of pulmonary thromboembolism and $32 \%$ history of thrombophilia, the most common was antiphospholipid syndrome (23\%). The most frequent presenting symptoms were dyspnea and fatigue; $20 \%$ presented syncopal episodes, with a time between the onset of symptoms and their diagnosis of 12 months. Most of the patients had marked symptoms, $79 \%$ being in functional class III and IV. The median pressure of the pulmonary artery was $50 \mathrm{mmHg}$ in the right catheterization, with pulmonary vascular resistance of 640 dyn.sec. $\mathrm{cm}^{-5}$ and systemic resistance of 1600 dyn.sec.cm ${ }^{-5}$. A $46.5 \%$ of the population received specific treatment for pulmonary hypertension, sildenafil ( $n: 25$; $34.2 \%$ ) and bosentan ( $n: 11 ; 15 \%$ ) being the most frequently used (14 in combination therapy and of these 6 received the sildenafil-bosentan combination). A little more than half were in anticoagulation management (60\%), half were taking warfarin and the remaining were on direct anticoagulants (rivaroxaban and apixaban the most frequent). Prior to the procedure, twothirds of the population received an inferior vena cava filter implant.

Regarding the surgical procedure, the median perfusion time was 292 minutes, the aortic clamp time was 120 minutes, and the circulatory arrest time was 64 minutes. Additional procedures were performed in 17 patients (23\%), with tricuspid plasty and the correction of an atrial septal defect being the most frequent; only 2 patients required coronary artery bypass graft surgery. Regarding the hemodynamic parameters after the surgical intervention, there was a significant decrease in parameters such as pulmonary artery systolic pressure (median $47 \mathrm{mmHg}$; change of $46 \%$ ), mean pulmonary artery pressure (median $30 \mathrm{mmHg}$; change of $40 \%$ ), pulmonary artery diastolic pressure (median $18 \mathrm{mmHg} ; 43.8 \%$ change), systemic vascular resistance (SVR) (median 916 dyn.sec.cm ${ }^{-5} ; 42.8 \%$ change) and pulmonary vascular resistance (PVR) (median 136 dyn.sec.cm ${ }^{-5}$; $79 \%$ change).

Complications related to the procedure occurred in a minority of cases (10\%), of which vascular lesions were the main ones; no patient died during the procedure. Half of the patients required inotropic support ( $\mathrm{n}: 39 ; 53 \%$ ) after the procedure and in a lesser percentage vasopressor support (n: 32; 43\%). $43 \%$ of the patients had reperfusion edema. The median stay in the intensive care unit was 6 days [IQR: 3-13], with a median of 2 days of mechanical ventilation [IQR:1-6] and a total time of hospitalization of 20 days [IQR:14-29].

Regarding mortality, there were 14 events (19.17\%) in the study period. Most of these ( $n$ : $9 ; 12.32 \%$ ) occurred at 30 days, septic shock being the main cause followed by cardiogenic etiology. Five deaths were recorded during the first 6 months; of these 3 due to pulmonary infectious complications and in 2 cases the cause could not be established.

The median lactate on day 1 was $4.65 \mathrm{mmol} / \mathrm{L}$ and on day 2 it was $1.62 \mathrm{mmol} / \mathrm{L}$ with a change of $2.87 \mathrm{mmol} / \mathrm{L}$, changes that were not significant. When performing the analysis between patients who died in-hospital (first 30 days) and those who did not obtain values for the first day of $4.11 \mathrm{mmol} / \mathrm{L}$ and 4.95 $\mathrm{mmol} / \mathrm{L}$ respectively. The value at day 2 was $1.68 \mathrm{mmol} / \mathrm{L}$ for the patients who died and 1.62 for those who did not die, with a delta of $1.77 \mathrm{mmol} / \mathrm{L}$ for the first group and $3.03 \mathrm{mmol} / \mathrm{L}$ for the second (Table 1). The variations in lactate levels stratified by results (mortality, in-hospital mortality) did not show statistically significant changes (Table 2).

In the multivariate Cox regression, no relationship was found with global or in-hospital mortality between the levels on day 1 , or on day 2 , such as the absolute change (Table 3). Lactate levels did not show a relationship with the time of invasive mechanical ventilation, with Standardized $\beta$ values of -0.27 (95\% $\mathrm{Cl}-1.81$ to $-0.16, \mathrm{p}=0.020)$ for the day $1 ;-0.25(95 \% \mathrm{Cl}-3.87$ to -0.14 , $\mathrm{p}=0.040$ ) for the day 2 and $-0.18(95 \% \mathrm{Cl}-0.16$ to $0.21, \mathrm{p}=0.130)$ for the lactate delta. The area under the curve were 0.51 for 30-days mortality and 0.61 for 6 -months mortality in day 1 (Figure 1), and 0.53 for 30 -days mortality and 0.51 for 6 -months mortality in day 2 (Figure 2) to predict the mortality outcomes.

\section{Discussion}

The results of the behavior and kinetics of lactate are presented as its prognostic performance in a population undergoing pulmonary thromboendarterectomy in a referral center. The analysis between lactate level and mechanical ventilation did not show a relationship, mentioning the fact that the average number of days of mechanical ventilation was 2 days, with a significant percentage of reperfusion edema. The lactate performance assessed by the area under the curve is generally regular both on day 1 and on day 2 in relation to 


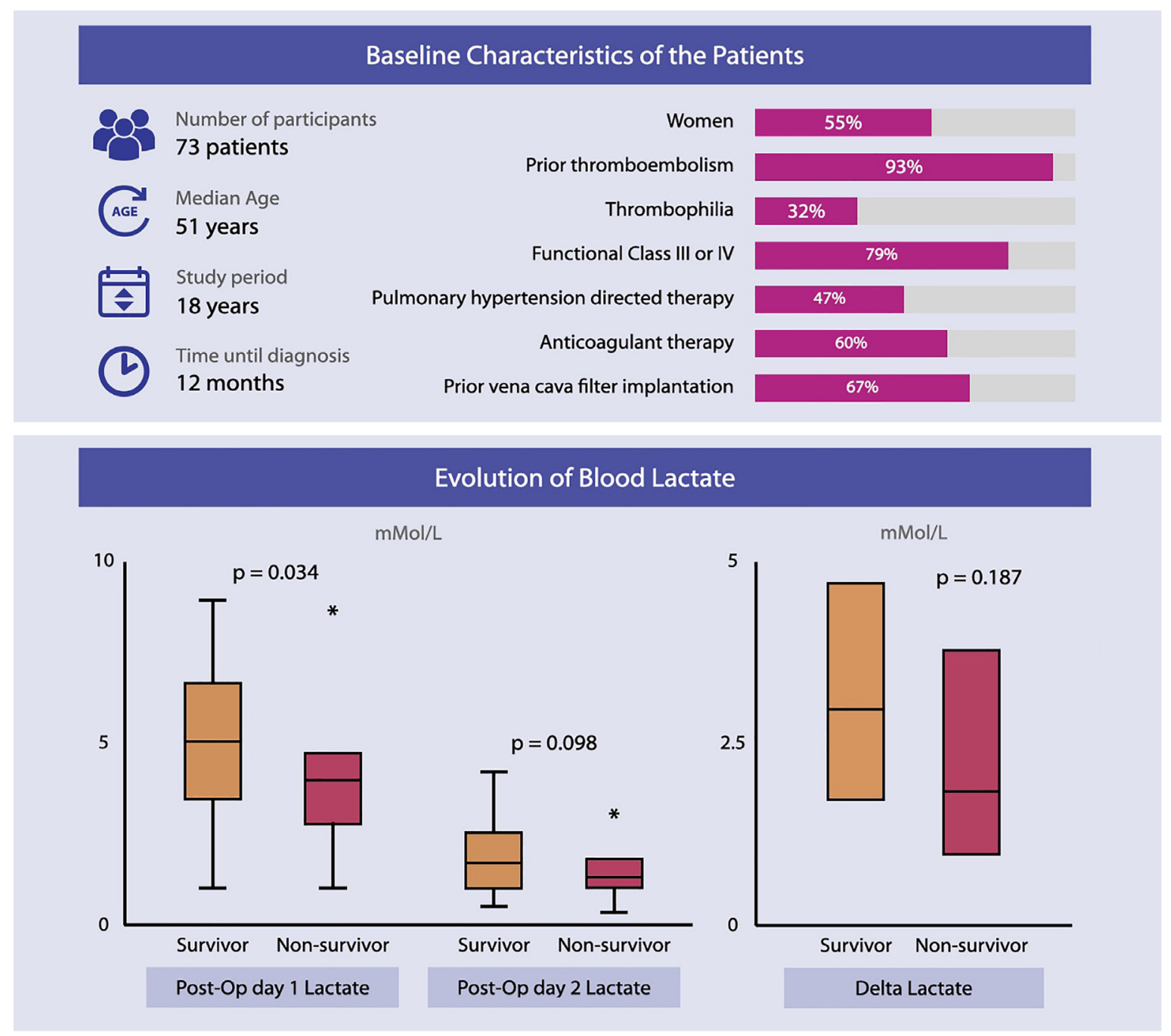

Central figure. Arterial lactate levels and their prognostic value in patients undergoing pulmonary thromboendarterectomy

the outcome of death. It is necessary to confirm these results in prospective studies with an adequate follow-up time and a larger sample size.

In a cardiac surgery, extracorporeal circulation (EC) allows surgeons to treat a wide range of heart disease while machines maintain circulation and oxygenation of human blood ${ }^{(5)}$. Initially, the creation of embolic particles in response to trauma was a common adverse effect of EC ${ }^{(16)}$. However, with the passage of time, biomaterials were created, and pharmacological therapies were implemented that reduced these potential adverse events, which in turn improved the results of the therapy. Despite contemporary success, patients undergoing cardiac surgery

Table 1. Lactate levels at day 1,2 and delta lactate by global mortality cases.

\begin{tabular}{lcccc}
\hline & All & Mortality & Non-Mortality & P-Value* $^{*}$ \\
\hline$n$ & 73 & 15 & 58 & \\
Lactate day 1, mmol/L & $4.65[3.44-6.26]$ & $4.00[2.81-4.72]$ & $5.15[3.50-6.68]$ & 0.034 \\
Lactate day 2, mmol/L & $1.62[0.96-2.43]$ & $1.28[1.00-1.77]$ & $1.68[1.00-2.49]$ & 0.098 \\
Lactate delta, $\mathrm{mmol} / \mathrm{L}$ & $2.87[1.63-4.46]$ & $1.85[1.00-3.80]$ & $2.98[1.73-4.72]$ & 0.187 \\
\hline
\end{tabular}

Data are presented as median [interquartile range], ${ }^{*}$ Obtained from Mann Whitney U test 
Table 2. Lactate levels at day 1, 2 and delta lactate, by in-hospital mortality cases.

\begin{tabular}{lcccc}
\hline & All & Intrahospital Mortality & Non- Intrahospital Mortality & P-Value* \\
\hline$n$ & 73 & 10 & 63 & \\
Lactate day 1, mmol/L & $4.65[3.44-6.26]$ & $4.11[2.11-4.56]$ & $4.95[3.47-6.68]$ & 0.033 \\
Lactate day 2, mmol/L & $1.62[0.96-2.43]$ & $1.68[1.00-2.15]$ & $1.62[1.00-2.46]$ & 0.602 \\
Lactate delta, $\mathrm{mmol} / \mathrm{L}$ & $2.87[1.63-4.46]$ & $1.77[0.75-2.83]$ & $3.03[1.75-4.88]$ & 0.057 \\
\hline
\end{tabular}

Data are presented as median [interquartile range], *Obtained from Mann Whitney $\mathrm{U}$ test

have complications related to the inappropriate inflammatory response developed. Potential triggers related to this response have been endotoxemia, ischemia-reperfusion injury, and exposure of the blood to non-endothelial surfaces ${ }^{(17)}$. There is an increase in the recruitment of leukocytes and proinflammatory cytokines, secondary to the activation of the cellular and humoral immune systems ${ }^{(18)}$. The complications associated with the development of this systemic inflammatory response syndrome are: myocardial dysfunction, acute renal failure, neurological dysfunction, respiratory failure, bleeding and finally multiple organ failure (MOF) ${ }^{(18)}$, that has been correlated with an increase in the probability of dying as well as in morbidity in patients undergoing cardiovascular surgery ${ }^{(18)}$.

Hyperlactatemia $(\mathrm{HL})$ in patients who undergo cardiac surgery with CPB can be due to tissue hypoxia, nonhypoxic causes such as drug therapy, cardioplegia solution, hypothermia, and CPB itself ${ }^{(19)}$. Demers et al. ${ }^{(20)}$, found that in adult patients undergoing cardiac surgery, $\mathrm{HL}$ is detected in $10-20 \%$ of patients and was associated with significant postoperative morbidity and mortality. In a study done by Broder and Weil, more than $88 \%$ of patients who had blood a lactate level of $>4.0 \mathrm{mmol} / \mathrm{L}$ had a high risk of mortality due to circulatory shock ${ }^{(7)}$. The same authors documented that the chances of survival from shock declines from 90 to $10 \%$ as blood lactate levels escalates from 2.0 to $8.0 \mathrm{mmol} / \mathrm{L}^{(8)}$.

Patients undergoing cardiac surgery under $\mathrm{CPB}$, despite having normal arterial blood gases ( $A B G s$ ), may still experience lactic acidosis secondary to tissue hypoperfusion. Therefore, monitoring blood lactate levels in cardiac surgery patients might be more sensitive than ABG analysis alone and will thereby help in early detection of an imbalance between oxygen supply and demand. The SIRS associated with CPB and its previously mentioned complications may be an additional cause of tissue hypoperfusion and hyperlactatemia.

To date there are no data on the behavior of the lactate in patients undergoing pulmonary thromboendarterectomy. The findings of the population show that, despite the requirement of a significant proportion of vasoactive supports, the patients achieved concentrations lower than $2 \mathrm{mmol} / \mathrm{L}$ during day 2 after the intervention. Notably, patients in the in-hospital mortality group presented lower levels on day 1 compared to those who did not die, which is consistent with a lower delta between day 1 and 2 in this group $(1.77 \mathrm{mmol} / \mathrm{L})$ compared to patients that survived (3.03 mmol/L). However, no association with mortality could be established, even when adjusted to clinical, surgical and hemodynamic variables of interest.

The present study has the following limitations: the retrospective nature of the study means that all biases or confounding factors cannot be controlled for; the small number of patients and events makes the findings regarding mortality and complications not generalizable and does not rule out an existing relationship. The sample size could be a limitation for having a study with adequate power. The levels were only measured at two points during the first day and 24 hours after it, so the lack of relationship with the outcomes can be explained by the compound's own

Table 3. Cox regression analyses for lactate levels and overall mortality (in-hospital and during follow-up) and in-hospital mortality.

\begin{tabular}{lcccc}
\hline & \multicolumn{2}{c}{ Mortality } & \multicolumn{2}{c}{ Intrahospital Mortality } \\
\hline & HR [95\% Cl] & P-Value & HR [95\% Cl] & P-Value \\
\hline Lactate day 1 & $0.90[0.72-1.11]$ & 0.320 & $0.78[0.60-1.02]$ & 0.067 \\
Lactate day 2 & $0.71[0.41-1.22]$ & 0.210 & $0.77[0.39-1.50]$ & 0.440 \\
Lactate delta & $0.93[0.72-1.21]$ & 0.600 & $0.96[0.49-1.06]$ & 0.096 \\
\hline
\end{tabular}

In total 14 patients died, 9 (12.32\%) occurred at 30 days. Cox regression analyses were performed. HR: hazard ratio. 


\section{A}

Day-1 lactate and 30-days mortality

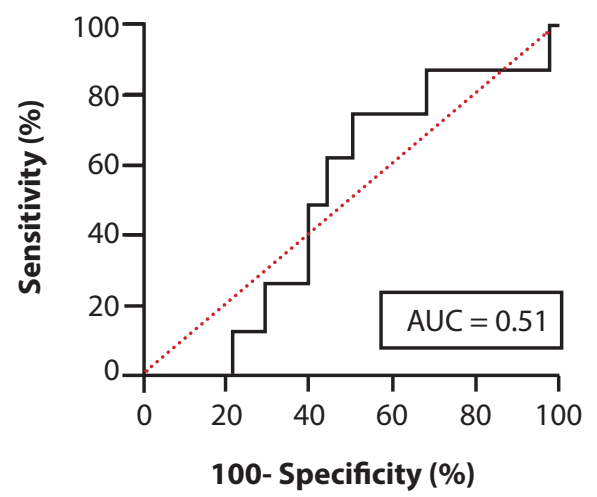

B

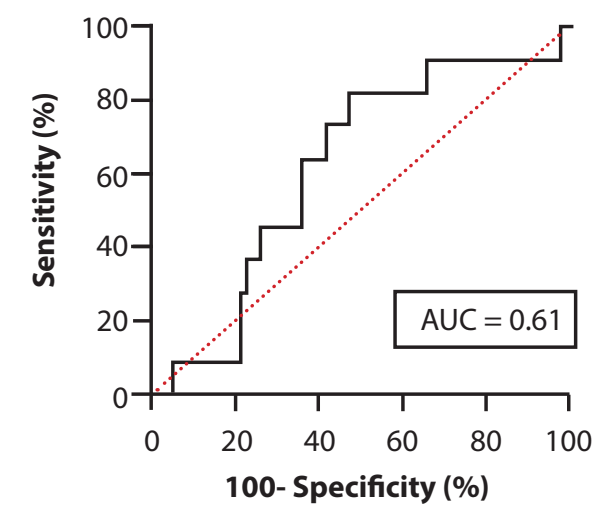

Figure 1. Area under the curver of lactate levels at after surgery in relation to mortality. A. 30-day mortality. B. mortality at 6 months.

kinetics and the lack of data in days after or close to the events. Also, a relationship was not made with the blood $\mathrm{pH}$ level as with other metabolic parameters in the studied population.

\section{Conclusions}

Lactate behavior in patients undergoing pulmonary thromboendarterectomy for chronic thromboembolic pulmonary disease shows a rapid change during the first hours after the surgical procedure and no relationship with in-hospital mortality was found in the present study. However, studies with a larger population and
A

Day-1 lactate and 30-days mortality

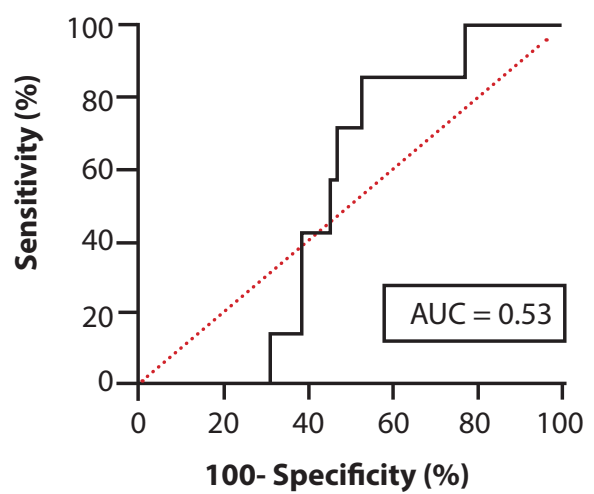

B

Day-2 lactate and 6-months mortality

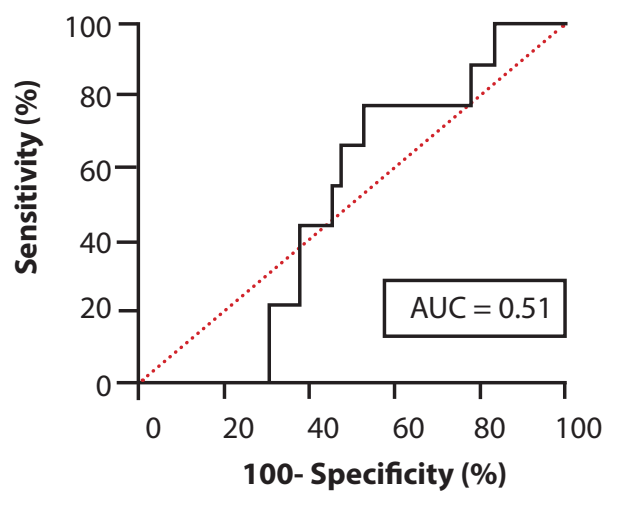

Figure 2. Area under the curve of lactate levels on day 2 after surgery in relation to mortality. A. 30-day mortality. B. Mortality at 6 months.

more frequent measurements should be carried out to validate these results.

Authors' Contributions: CFRR, CISG, JCRI, contributed to the acquisition of data, to the conception or design of the study and drafted the manuscript.

GACA, MAU, SSB, PC, CG, AL, AP, JDUM, MYC: contributed interpretation of data and critical revision of the article for important intellectual content.

Acknowledgement: Dr. Carlos Pereda for the central image.

\section{Referencias bibliográficas}

1. Madani MM. Surgical Treatment of Chronic Thromboembolic Pulmonary Hypertension: Pulmonary Thromboendarterectomy. Methodist Debakey Cardiovasc J. 2016;12(4):213-218. doi: 10.14797/ mdcj-12-4-213.
2. Riedel $\mathrm{M}$, Stanek V, Widimsky J, Prerovsky I. Longterm follow-up of patients with pulmonary thromboembolism. Late prognosis and evolution of hemodynamic and respiratory data. Chest. 1982;81(2):151-8. doi: 10.1378/chest.81.2.151. 
3. Mayer E, Jenkins D, Lindner J, D'Armini A, Kloek J, Meyns B, et al. Surgical management and outcome of patients with chronic thromboembolic pulmonary hypertension: results from an international prospective registry. J Thorac Cardiovasc Surg. 2011;141(3):702-10. doi: 10.1016/j.jtcvs.2010.11.024.

4. Madani MM, Auger WR, Pretorius V, Sakakibara N, Kerr KM, $\mathrm{Kim} \mathrm{NH}$, et al. Pulmonary endarterectomy: recent changes in a single institution's experience of more than 2,700 patients. Ann Thorac Surg. 2012;94(1):97-103; discussion 103. doi: 10.1016/j. athoracsur.2012.04.004.

5. Sarkar M, Prabhu V. Basics of cardiopulmonary bypass. Indian J Anaesth. 2017;61(9):760-767. doi: 10.4103/ija.IJA_379_17.

6. Park SJ, Kim SP, Kim JB, Jung SH, Choo SJ, Chung CH, et al. Blood lactate level during extracorporeal life support as a surrogate marker for survival. J Thorac Cardiovasc Surg. 2014;148(2):714-20. doi: 10.1016/j.jtcvs.2014.02.078.

7. Broder G, Weil MH. Excess lactate: an index of reversibility of shock in human patients. Science. 1964;143(3613):1457-9. doi: 10.1126/ science.143.3613.1457.

8. Weil MH, Afifi AA. Experimental and clinical studies on lactate and pyruvate as indicators of the severity of acute circulatory failure (shock). Circulation. 1970;41(6):989-1001. doi: 10.1161/01. cir.41.6.989.

9. Vincent JL, De Backer D. Circulatory shock. N Engl J Med. 2013;369(18):1726-34. doi: 10.1056/NEJMra1208943.
10. Nichol AD, Egi M, Pettila V, Bellomo R, French C, Hart G, et al. Relative hyperlactatemia and hospital mortality in critically ill patients: a retrospective multi-centre study. Crit Care. 2010;14(1):R25. doi: $10.1186 /$ cc8888.

11. Haas SA, Lange T, Saugel B, Petzoldt M, Fuhrmann V, Metschke M, et al. Severe hyperlactatemia, lactate clearance and mortality in unselected critically ill patients. Intensive Care Med. 2016;42(2):20210. doi: 10.1007/s00134-015-4127-0.

12. Ranucci $M$, De Toffol B, Isgrò $G$, Romitti F, Conti D, Vicentini M. Hyperlactatemia during cardiopulmonary bypass: determinants and impact on postoperative outcome. Crit Care. 2006;10(6):R167. doi: $10.1186 /$ cc5113.

13. Basaran M, Sever K, Kafali E, Ugurlucan M, Sayin OA, Tansel T, et al. Serum lactate level has prognostic significance after pediatric cardiac surgery. J Cardiothorac Vasc Anesth. 2006;20(1):43-7. doi: 10.1053/j. jvca.2004.10.010.

14. Toraman F, Evrenkaya S, Yuce M, Aksoy N, Karabulut H, Bozkulak $Y$, et al. Lactic acidosis after cardiac surgery is associated with adverse outcome. Heart Surg Forum. 2004;7(2):E155-9. doi: 10.1532/ HSF98.20041002.

15. Khosravani H, Shahpori R, Stelfox HT, Kirkpatrick AW, Laupland KB. Occurrence and adverse effect on outcome of hyperlactatemia in the critically ill. Crit Care. 2009;13(3):R90. doi: 10.1186/Cc7918. 